\title{
Structural stability of 8090 Al-Li Base Alloy studied by TEM
}

\author{
A.L.A. Rocha., I. G. Solórzano., and F.A.Darwish \\ Department of Materials Science and Metallurgy, PUC-Rio, Rio de Janeiro- Brazil.
}

Over the past few decades, considerable effort has been directed towards the study of Al-Li base alloys. This has been largely motivated by the appreciable improvement in the specific properties the presence of Li brings about. However, the use of $\mathrm{Cu}, \mathrm{Mg}$ and $\mathrm{Zr}$ as additional alloying elements has been a common practice with the objective of promoting the formation of more uniformly distributed second phase precipitates, thus considerably improving both the monotonic and cyclic mechanical behaviors over those of binary Al-Li alloys. [1,2]

The material used for the present work was an 8090 T3 Al-Li base alloy supplied by Pechiney Recherche in the form of a $3.3 \mathrm{~mm}$ thick plate, having the following chemical composition (in weight \%): $2.4 \mathrm{Li} ; 1.2 \mathrm{Cu} ; 0.6 \mathrm{Mg}$; $0.12 \mathrm{Zr}$; balance $\mathrm{Al}$.

The as received alloy was submitted to non-conventional two-stage heat treatment consisting of retrogression and reaging, where the alloy was solution annealed at $550^{\circ} \mathrm{C}$ for 1 hour, quenched in water and then reaged. Reaging treatment was carried out at two different temperatures of 150 and $200^{\circ} \mathrm{C}$ for different time intervals ranging from 10 to 5000 minutes. Specimens for TEM analysis were prepared following the conventional procedure consisting of slicing, mechanical thinning down to $150 \mu \mathrm{m}$ and finally electrolytic thinning using the double jet technique in a solution composed, in volume $\%$, of $30 \%$ nitric acid and $70 \%$ methanol, kept at $-20^{\circ} \mathrm{C}$. TEM investigation was then conducted using a Jeol 2010 microscope operating at $200 \mathrm{kV}$ under diffraction contrast mode. [3]

The results obtained have indicated that the as-received alloy contains a dispersion of coherent $\delta$ 'phase about $20 \mathrm{~nm}$ in size (Fig. 1). The presence of other phases such as $\mathrm{Al}_{3} \mathrm{Zr}$ and $\mathrm{S}^{\prime}$ phase (Fig. 2) could be observed only after retrogression and reaging treatments. Aging at $150^{\circ} \mathrm{C}$ during 1000 minutes results in a homogeneous precipitation of very fine donut shaped particles (Fig. 3), which in fact correspond to a nano-composite of $\mathrm{Al}_{3} \mathrm{Zr}$ surrounded by $\delta^{\prime}\left(\mathrm{Al}_{3} \mathrm{Li}\right)$. On the other hand, TEM observations indicate the presence of persistent inclusions, which are independent of the heat treatment cycle induced in the sample. Indeed, EDS analysis (Fig. 4) has shown such inclusions to be iron containing, which is considered typical in $\mathrm{Al}$ alloys. It is interesting to note that, in virtue of the rather robust size (about $1 \mu \mathrm{m}$ ) of these inclusions, dark field image conditions allow one to detect the accommodation between different crystallographic domains, (Fig. 5). Another finding worthy of mentioning is related to the observation, in the matrix, of nanoscale areas with crystalline discontinuities, which may correspond to an amorphous structure, as revealed by the HREM of Fig. 6. These observations seem to be striking and invite further detailed investigation. [4]

\section{References}

[1] T.H. Sanders, Jr and E. A. Starke, Jr. Second International Aluminum-Lithium Conference, (1983), 1-16.

[2] I. G. Solórzono, F. A. Darwish, M. C. De Macedo and S. O. De Menezes. accepted for publication in Materials Science and Engineering A, 2003.

[3] V. Komisarov, M. Talianker, B. Cina.. Material Science and Engineering A (1998) 39-49.

[4] This work has been supported by CNPq, Brazil. 

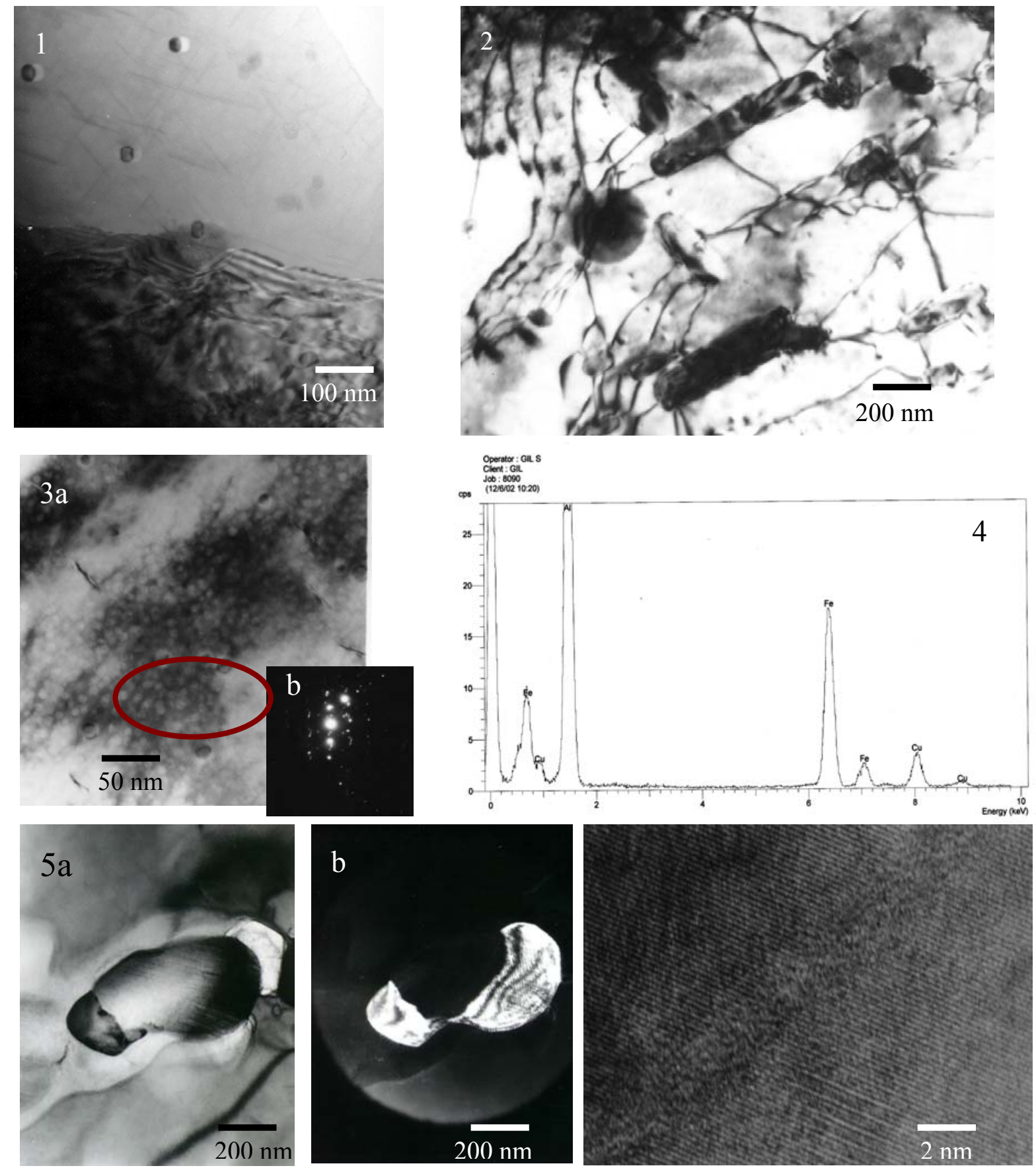

Figure 1- Bright field image of the as-received 8090 alloy showing coherent precipitates.

Figure 2 - Bright field image of the alloy aged at $150^{\circ} \mathrm{C}$ during 5000 minutes showing S' phase. Figure 3 - (a) Bright field image of donut shaped nano-composite of $\mathrm{Al}_{3} \mathrm{Zr}$ phase surrounded by $\mathrm{Al}_{3} \mathrm{Li}$ detected in a specimen reaged at $150^{\circ} \mathrm{C}$ during 1000 and (b) Select area diffraction pattern corresponding to figure $3 \mathrm{a}$.

Figure 4 - EDS spectrum of the alloy showing the presence of iron.

Figure 5 - TEM micrographs of iron rich inclusion (a) bright field and (b) dark field.

Figure 6 - HREM image of the alloy aged at $200^{\circ} \mathrm{C}$ during 1000 minutes. 